\title{
Combination of SB431542, CHIR99021 and PD0325901 has a synergic effect on abrogating valproic acid-induced epithelial-mesenchymal transition and stemness in HeLa, 5637 and SCC-15 cells
}

\author{
YANMIN ZHANG ${ }^{1 *}$, YUSEN ZHANG $^{2 *}$, MINGHUA LI $^{1}$, FANHUA MENG $^{3}$, \\ ZHENDONG YU $^{1}$, YUN CHEN $^{2}$ and GUANGHUI CUI ${ }^{2}$ \\ ${ }^{1}$ Central Laboratory, ${ }^{2}$ Ultrasound Department and ${ }^{3}$ Reproductive Medicine Center, Peking University Shenzhen Hospital, \\ Shenzhen, Guangdong 518036, P.R. China
}

Received November 15, 2018; Accepted March 28, 2019

DOI: $10.3892 / o r .2019 .7088$

\begin{abstract}
Epithelial-mesenchymal transition (EMT) plays an important role in cancer progression, metastasis and drug resistance, and recent studies have revealed that neoplastic epithelial cells regain the stem cell state through EMT. Single-agent targeted cancer therapy frequently fails due to acquired drug resistance. Therefore, multi-agent targeted therapy exhibits advantages in fighting cancer cells. In the present study, small molecule inhibitors SB431542 (ALK inhibitor), CHIR99021 (GSK3 pathway inhibitor), PD0325901 (MEK/ERK inhibitor) and valproic acid (VPA; HDAC inhibitor) were applied individually or in combination to HeLa uterine cervix carcinoma cells, 5637 bladder cancer cells and SCC-15 squamous cell carcinoma cells to clarify their potential effects on cancer cells. Cell morphological alterations, pluripotency and EMT-related gene expression, cell growth rate, cell migration, signal transduction, cell cycle arrest, $\mathrm{CD} 24{ }^{-} \mathrm{CD} 44^{+}$cell percentage, and in vivo tumor clump formation were evaluated. The results of the present study revealed that VPA treatment induced EMT morphology, upregulated the expression of pluripotency and EMT-related genes, promoted migration and increased CD24/CD $44^{+}$cell percentage in all three cell lines. PD0325901, SB431542 and CHIR99021 in combination could significantly inhibit cell growth, suppress expression of pluripotency and EMT-related
\end{abstract}

Correspondence to: Dr Guanghui Cui or Dr Yun Chen, Ultrasound Department, Peking University Shenzhen Hospital, 1120 Lianhua Road, Futian, Shenzhen, Guangdong 518036, P.R. China

E-mail: cuiguanghui175@aliyun.com

E-mail: cyun126@126.com

\section{*Contributed equally}

Key words: epithelial-mesenchymal transition, cancer stem cell, kinase, small molecule inhibitor, cell invasion genes, curb cell migration, cause cell cycle arrest, decrease $\mathrm{CD} 24 / \mathrm{CD} 44^{+}$cell percentage in cell spheres, and delay in vivo cell clump formation of cancer cells. These data indicated that VPA may serve as an EMT and cancer stem cell-promoting agent that may be useful in establishing a screening system for potential anticancer stem cell drugs. The combined inhibition of MEK/ERK, ALK and GSK3 was revealed to be an effective measure for eliminating cancer stem cells.

\section{Introduction}

Small molecules that interact with specific targets in signaling and epigenetic pathways have been demonstrated to be useful agents for modulating cell differentiation. These agents can enhance reprogramming of differentiated cells to pluripotent stem cells (1-4) and also induce epithelial-mesenchymal transition (EMT) in cancer cells in vitro (5-9). EMT is a crucial trans-differentiation process that occurs during embryogenesis and in adult tissue repair and also plays an important role during cancer progression $(10,11)$. During EMT, epithelial cells acquire mesenchymal cell morphology, leading to increased migration capacity and stemness (12-15).

Numerous studies have demonstrated the involvement of epigenetic changes such as histone acetylation/deacetylation in cancer development. Therefore, targeting histone deacetylase complexes (HDACs) in cancer is a potential anticancer therapy approach (16). The small molecule valproic acid (VPA) inhibits HDACs, resulting in relief of HDAC-dependent transcriptional repression. Previous studies revealed that VPA regulated EMT-related gene expression in alveolar epithelial cells and induced invasion of human melanoma cells in vitro via regulation of $\mathrm{N}$-cadherin expression and RhoA activity $(17,18)$.

TGF- $\beta 1$ signaling plays a vital role in EMT. The small molecule SB431542 inhibits activation of the activin receptor-like kinase (ALK) receptors 4, 5 and 7, which are key members of the TGF- $\beta$ signaling pathway. Inhibition of TGF- $\beta 1 /$ Smad signaling was revealed to lead to repression of EMT in esophageal squamous cell carcinoma by downregulating the expression of $\mathrm{N}$-cadherin and vimentin and 
upregulating the expression of E-cadherin. TGF- $\beta 1$ signaling blockade attenuated gastric cancer cell-induced peritoneal mesothelial cell fibrosis and alleviated peritoneal dissemination both in vitro and in vivo, and sensitized drug-resistant pancreatic cancer cells to gemcitabine (19-21).

Disrupted activation of mitogen-activated/extracellularsignal-regulated protein kinases (MEK) has been indicated in developmental malformation and carcinogenesis. MEK inhibitor PD0325901 significantly reduced the growth of papillary thyroid carcinoma cells in vitro and in vivo (22). Combination treatment using PD0325901 and SRC inhibitors synergistically abrogated tumor cell growth and induced mesenchymal-epithelial transition (MET) in non-small cell lung carcinoma. Combined inhibition of PKC and MEK inhibited the proliferation of melanoma cell lines (23).

Glycogen synthase kinase-3 (GSK3) is an important regulator of cellular metabolism that plays complicated roles in some types of cancer. The GSK3 inhibitor CHIR99021 dose-dependently reduced the proliferation of three NSCLC cell lines (6). Inhibition of glycogen synthase kinase-3 activity triggered an apoptotic response through JNK-dependent mechanisms and induced prosurvival autophagic signals in human pancreatic cancer cells (24).

We hypothesized that although some targeted therapeutics initially were designed as antiproliferative agents, some agents may also inhibit EMT initiation since proliferation and EMT are regulated by similar signaling pathways. Therefore, targeting EMT using inhibitors represents a promising therapeutic strategy for treatment of cancer with an invasive phenotype.

It is recognized that a signaling pathway may crosstalk with other pathways and lead to malignant cells mutating quickly due to genome instability and DNA imprecise replication, causing frequent failure of single-agent targeted therapy (25-27). As a result, studies have evaluated the use of drug combinations in abrogating signaling pathways crosstalk to regain treatment sensitivity $(28,29)$. If one inhibitor is not effective in a particular cancer cell, other inhibitors may still be functional leaving cancer cells treated with combination inhibitors less chance for survival.

In the present study, we aimed to clarify the potential effects of various inhibitors the HDAC inhibitor VPA (V), the GSK3 inhibitor CHIR99021 (C), the MEK inhibitor PD0325901 (P) and the ALK inhibitor SB431542 (S) and their combinations on several cancer cell lines, including the uterine cervix carcinoma cell line HeLa, the bladder cancer cell line 5637 and the squamous cell carcinoma cell line SCC-15.

\section{Materials and methods}

Animals and cell lines. Thirty 4-week old female athymic Swiss nude mice (weight range, 16-20 g) were purchased from the Medical Experimental Animal Center of Guangdong Province China. They were maintained in a specific pathogen-free (SPF) room at constant temperature $\left(20^{\circ} \mathrm{C}\right)$ and humidity $(45 \%)$ on a 12-h light/dark cycle, and had free access to sterile laboratory chow and tap water. Animal experiment approval was obtained from the Ethics Committee of Peking University Shenzhen Hospital (Shenzhen, China). Chinese laws concerning animal caring and treatment were strictly followed during the experiments, and the study complied with the ARRIVE guidelines (https://www.nc3rs.org.uk/arrive-guidelines).

The HeLa uterine cervix carcinoma cell line (CBP60232), the SCC-15 squamous cell carcinoma cell line (CBP61034) and the 5637 bladder cancer cell line (CBP60309) were provided by COBIOR Cell Bank (Nanjing, China; http://www.cobioer. com), and maintained in Dulbecco's modified Eagle's medium (DMEM; Gibco; Thermo Fisher Scientific, Inc., Waltham, MA, USA) supplemented with $10 \%$ heat inactivated fetal bovine serum (FBS; HyClone; GE Healthcare, Chicago, IL, USA), $100 \mathrm{U} / \mathrm{ml}$ potassium penicillin, $100 \mathrm{U} / \mathrm{ml}$ streptomycin and $2 \mathrm{mM}$ glutamine. Cells were incubated at $37^{\circ} \mathrm{C}$ in a chamber with $5 \% \mathrm{CO}_{2}$ and $95 \%$ humidity.

Small molecules. SB431542, PD0325901 and CHIR99021 (Stemgent, Inc., Cambridge, MA, USA) and VPA (SigmaAldrich; Merck KGaA, Darmstadt, Germany) were dissolved in dimethyl sulfoxide (DMSO; Sigma-Aldrich; Merck KGaA) and diluted in DMEM. Cells were treated with medium containing a single inhibitor or inhibitor combinations, and medium was changed every other day. The recommended concentration of the single inhibitor $(0.5 \mu \mathrm{M} / 1 \mathrm{PD} 0325901,2 \mu \mathrm{M} / 1 \mathrm{SB} 431542$, $3 \mu \mathrm{M} / 1$ CHIR99021 and $0.5 \mathrm{mM} / 1 \mathrm{VPA}$ ) in this experiment was safe to cell viability (safe concentration) and previously used in reprogramming of differentiated cells to pluripotent stem cells by promoting MET, the reverse process of EMT, which is an important process in cell dedifferentiation (1-4).

Quantitative real-time $R T-P C R$. Total RNA was isolated using the RNase Mini kit (Qiagen, Inc., Valencia, CA, USA). A High Capacity RNA-to-cDNA kit (Applied Biosystems; Thermo Fisher Scientific, Inc.) was used to reverse-transcribe $1 \mu \mathrm{g}$ of RNA into cDNA with MMLV Reverse Transcriptase and random primers according to the manufacturer's instructions $\left(85^{\circ} \mathrm{C}, 5 \mathrm{sec}\right.$ and $37^{\circ} \mathrm{C}$ for $1 \mathrm{~h}$ ). Real-time PCR was performed using specific primers under optimal reaction conditions $\left(94^{\circ} \mathrm{C}, 30 \mathrm{sec} ; 60^{\circ} \mathrm{C}, 35 \mathrm{sec} ; 72^{\circ} \mathrm{C}, 40 \mathrm{sec}\right.$; 30 cycles) to quantify gene expression using SYBR-Green RT-PCR reagents (Applied Biosystems; Thermo Fisher Scientific, Inc.). The $2^{-\Delta \Delta \mathrm{Cq}}$ method (30) was used to analyze relative gene expression level. Table I lists the primers used in the present study.

Cell viability assay. Cell viability was assessed using the Cell Counting Kit-8 (CCK-8) assay (Roche Molecular Biochemicals, Mannheim, Germany). Briefly, treated cells were seeded in 96-well plates at a density of $1 \times 10^{3} /$ well and cultured for another $24 \mathrm{~h}$. Cell viability was evaluated using the kit according to the manufacturer's instructions and results were detected using a Model 680 microplate reader (Bio-Rad Laboratories, Hercules, CA, USA). All experiments were conducted in triplicate.

Cell invasion assays. Treated cells ( $2 \times 10^{4} /$ well) were seeded in a 24-well plate with a Millicell cell culture insert containing polycarbonate filter membranes with $8-\mu \mathrm{m}$ diameter pores (BD Biosciences, Franklin Lakes, NJ, USA). Cells were maintained in DMEM supplemented with $1 \%$ FBS. The lower chamber contained DMEM supplemented with $10 \%$ FBS. The plates were incubated for $48 \mathrm{~h}$ at $37^{\circ} \mathrm{C}$ in a $5 \% \mathrm{CO}_{2}$ humidified 
Table I. Primers used in quantitative real-time RT-PCR.

Genes

PCR primers

E-cadherin

$\mathrm{N}$-cadherin

Vimentin

$\operatorname{Oct} 3 / 4$

Sox2

Nanog

GAPDH
Sense primer: 5'-TTCTGCTGCTCTTGCTGTTT-3'

Antisense primer: 5'-TGGCTCAAGTCAAAGTCCTG-3'

Sense primer: 5'-CCTGCGCGTGAAGGTTTGCC-3'

Antisense primer: 5'-CCAAGCCCCGCACCCACAA-3'

Sense primer: 5'-GCCCTTAAAGGAACCAATGA-3'

Antisense primer: 5'-AGCTTCAACGGCAAAGTTCT-3'

Sense primer: 5'-GACAGGGGGAGGGGAGGAGCTAGG-3'

Antisense primer: 5'-CTTCCCTCCAACCAGTTGCCCCAAAC-3'

Sense primer: 5'-GGGAAATGGGAGGGGTGCAAAAGAGG-3'

Antisense primer: 5'-TTGCGTGAGTGTGGATGGGATTGGTG-3'

Sense primer: 5'-CAGCCCCGATTCTTCCACCAGTCCC-3'

Antisense primer: 5'-CGGAAGATTCCCAGTCGGGTTCACC-3'

Sense primer: 5'-CATCAATGGAAATCCCATCA-3'

Antisense primer: 5'-TTCTCCATGGTGGTGAAGAC-3' incubator. Invasive cells in the lower chamber were stained with $0.1 \%$ (w/v) crystal violet. Images were captured and visualized using QCapture Pro (version 7.0 software; QImaging, Surrey, BC, Canada).

Western blot analysis. Total protein was extracted using the EpiQuik Whole Cell Extraction kit (AmyJet Scientific, Inc., Wuhan, China) and protein concentration was measured by Bradford DC protein assay (Bio-Rad Laboratories, Hercules, CA, USA). Equal amounts of protein samples (30 $\mu \mathrm{g})$ were separated on $12 \%$ Bis-Tris polyacrylamide gel by electrophoresis and transferred to polyvinylidene difluoride membranes (EMD Millipore, Temecula, CA, USA) which was pre-blocked with $5 \%(\mathrm{w} / \mathrm{v})$ skim milk (BD Biosciences) in a rotator for $2 \mathrm{~h}$ at room temperature. The membranes were incubated with anti-phosphorylated Smad1/2 (cat. no. 8828), Erk1/2 (cat. no. 9101) (Cell Signaling Technology, Inc., Danvers, MA, USA) and GS (cat. no. 07-817) primary antibodies (EMD Mililipore) (all at 1:1,000 dilution) at $4^{\circ} \mathrm{C}$, for $12 \mathrm{~h}$, followed by incubation with a goat anti-rabbit polyclonal horseradish peroxidase (HRP)-conjugated secondary antibody (cat. no. A0208) (Beyotime Institute of Biotechnology, Shanghai, China) (1:10,000 dilution in $1 \%$ milk/TBS) for $2 \mathrm{~h}$ at room temperature. Protein bands were visualized using a chemiluminescence detection kit (Amersham Biosciences; GE Healthcare, Piscataway, NJ, USA). The visualized bands were analyzed by Tanon 5220S image analysis system (Tanon Image software version 1.0; Tanon Science and Technology Co., Ltd., Shanghai, China).

Cell cycle analysis. Cell cycle fractions were determined by propidium iodide (PI) nuclear staining (Beyotime Institute of Biotechnology). Briefly, cells were grown on 6-well plates and treated with inhibitors or DMSO as control for 6 days. Cells were then harvested, fixed with $70 \%$ cold ethanol, and stained with PI staining buffer $[0.03 \mathrm{mg} / \mathrm{ml}$ PI, $0.1 \mathrm{mg} / \mathrm{ml}$ RNAse A, $0.1 \%$ Triton $\mathrm{X}-100$ in phosphate-buffered saline
(PBS)] for $30 \mathrm{~min}$ at $25^{\circ} \mathrm{C}$. Flow cytometry was performed using a BD LSR II flow cytometer (BD Biosciences). At least 50,000 cell events were collected per sample and cell cycle analysis was performed using FlowJo software (version 10.0; FlowJo, LLC, Ashland, OR, USA).

Sphere formation and stemness-related marker examination. Cells in single cell suspension were plated into ultralow attachment $60 \mathrm{~mm}$ plates (Corning Inc., Corning, NY, USA) at a density of $1 \times 10^{5}$ cells/plate in stem cell media: DMEM supplemented with $20 \mathrm{ng} / \mathrm{ml}$ human basic fibroblast growth factor, $20 \mathrm{ng} / \mathrm{ml}$ epidermal growth factor (Invitrogen; Thermo Fisher Scientific, Inc.), $100 \mathrm{ng} / \mathrm{ml}$ insulin (Thermo Fisher Scientific, Inc.) and $100 \mathrm{U} / \mathrm{ml}$ penicillin/streptomycin. Cells were then subjected to different inhibitor treatments. Single cell suspension of the spheres was prepared for assessment of CD $24^{-} / \mathrm{CD} 24^{+}$percentage by flow cytometry.

In vivo cancer cell clump formation test. Cells (5x10 5 cells) isolated from VPA and V+C+S+P-treated HeLa, SCC-15 and 5637 cancer cell spheres were injected subcutaneously into the flank of female athymic Swiss nude mice, respectively (total 30 mice were randomly separated into six groups, 5 mice in each group; two groups were assigned to each cell line, one group for injection of VPA-treated cells, and the other group for injection of $\mathrm{V}+\mathrm{C}+\mathrm{S}+\mathrm{P}$ treated cells). Cancer cell clump growth at the site of injection was monitored twice a week with calipers. The mice were sacrificed 30 days after cancer cell injection by cervical vertebra dissociation after pentobarbital sodium anesthetization ( $40 \mathrm{mg} / \mathrm{kg}$ body weight). The cancer cell clumps were excised and weighted.

Statistical analysis. All data are presented as the mean \pm standard deviation (SD) from three independent experiments (three experiments were carried out under same conditions), except in the in vivo cancer cell clump formation test. Data were analyzed using SPSS software (version 11.0; SPSS, Inc., 

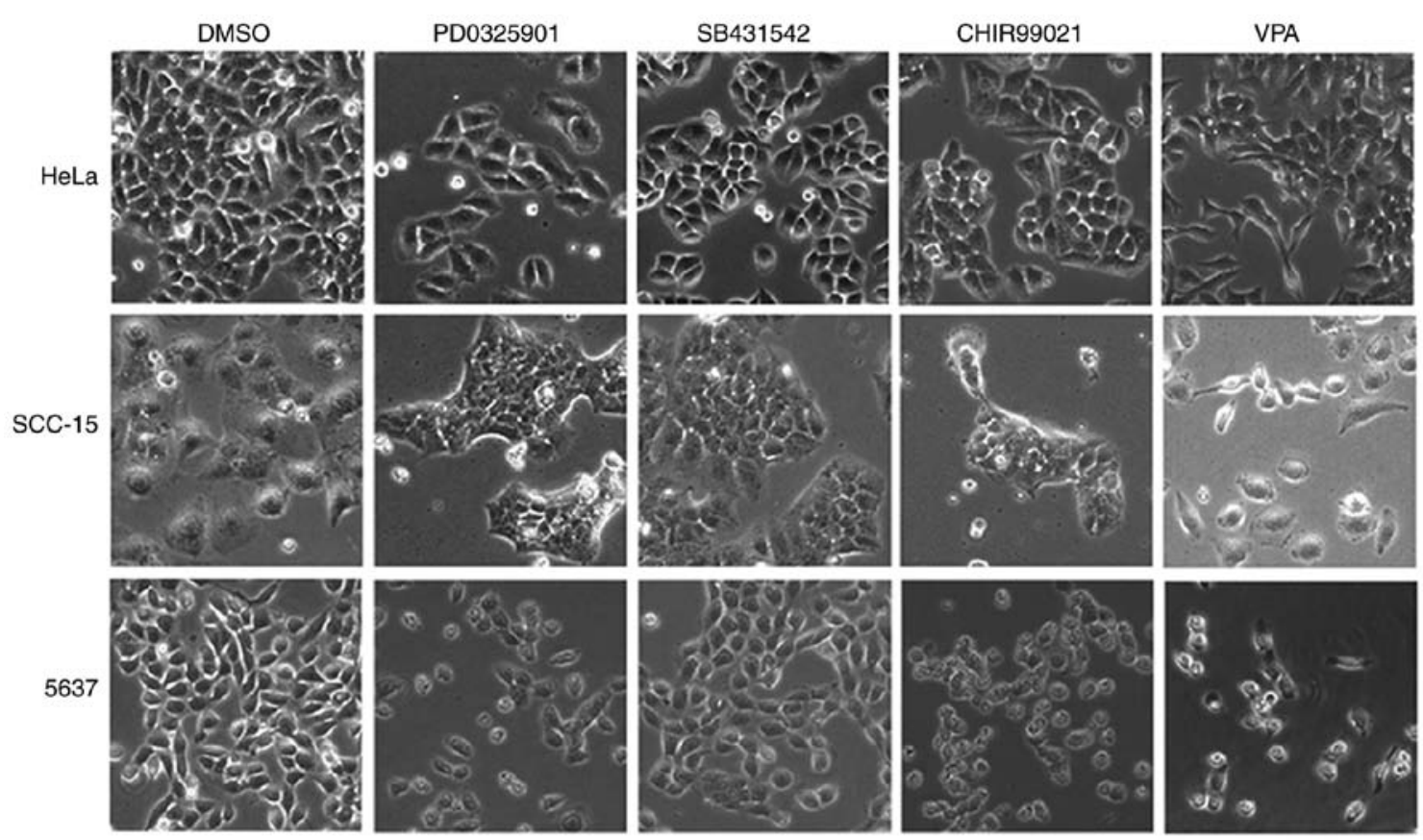

Figure 1. VPA leads to EMT phenotype of cancer cells. Spindle-shaped cells were observed in VPA-treated HeLa, SCC-15 and 5637 cells. In SB431542-, PD0325901-, CHIR99021-treated cells, EMT morphology change was not observed. DMSO served as a control (magnification, x100). VPA, valproic acid; EMT, epithelial-mesenchymal transition; DMSO, dimethyl sulfoxide.

Chicago, IL, USA). A Student's t-test was used in comparison between two groups, and one-way analysis of variance (ANOVA) with Dunnett's test was used in multiple comparisons to one control. P-values $<0.05$ were considered to indicate a statistically significant difference.

\section{Results}

VPA induces EMT phenotype in cancer cells. To investigate the influence of the small molecule inhibitors on cancer cell morphology, HeLa, SCC-15 and 5637 cells were treated with SB431542 (S; ALK inhibitor), PD0325901 (P; MEK inhibitor), CHIR99021 (C; GSK3 inhibitor), and VPA (V; HDAC inhibitor) at the recommended concentrations ( $0.5 \mu \mathrm{M} / 1 \mathrm{PD} 0325901$, $2 \mu \mathrm{M} / 1 \mathrm{SB} 431542,3 \mu \mathrm{M} / 1 \mathrm{CHIR} 99021$ and $0.5 \mathrm{mM} / 1 \mathrm{VPA}$ ) for 4-6 days, with medium changed every other day. Abundant spindle-shaped cells were observed in all three cell lines treated with VPA, suggesting that VPA treatment could lead to induction of EMT phenotype (Fig. 1). In contrast, the other three inhibitors did not exhibit similar effects in inducing spindle cell morphology. Cells treated with the DMSO control maintained their original morphology.

VPA promotes pluripotent transcription factor and EMT-related gene expression. To examine whether VPA induced cancer cell EMT and stemness, HeLa cells were treated with each of the inhibitors for 6 days and the gene expression levels of pluripotency-related transcription factors and EMT-related factors were evaluated. In HeLa cells treated with VPA, the gene expression of pluripotency-related transcription factors Oct3/4, Sox2, Nanog and EMT-related genes N-cadherin and vimentin were upregulated, while the MET-related E-cadherin gene was downregulated compared with the DMSO-treated control cells. In contrast, treatment with CHIR99021,
SB431542 or PD0325901 suppressed the gene expressions of pluripotent-related transcription factors and EMT-related genes to various levels (Fig. 2A).

Since single agent targeted therapy fails frequently in cancer treatment, numerous researchers have conducted investigation on a two-agent combination. Theoretically there is still a risk that cancer cells could develop the ability to survive with a two-agent combination. Thus, in the present study we assessed three-agent combination on cancer cells trying to inhibit signaling pathways in an extended range.

Since VPA upregulated EMT and cell pluripotency-related gene expression, and CHIR99021, SB431542 or PD0325901 suppressed the expression of these genes to various extents, different combinations of inhibitors $(\mathrm{V}+\mathrm{S}, \mathrm{V}+\mathrm{P}, \mathrm{V}+\mathrm{C}, \mathrm{V}+\mathrm{C}+\mathrm{S}$, $\mathrm{V}+\mathrm{C}+\mathrm{P}, \mathrm{V}+\mathrm{S}+\mathrm{P}$, or $\mathrm{V}+\mathrm{C}+\mathrm{S}+\mathrm{P}$ ) were then used to treat $\mathrm{HeLa}$ cells for 6 days to examine whether any of the inhibitors or inhibitor combinations could counteract the effects of VPA. Single and combination treatments could counteract the effect of VPA to various extents. The $\mathrm{C}+\mathrm{S}+\mathrm{P}$ combination exerted the strongest suppressive effect on pluripotency and EMT-related gene expression in the presence of VPA compared with single and two inhibitor combinations (Fig. 2B).

Since VPA upregulated EMT and cell pluripotency-related gene expression in $\mathrm{HeLa}$ cells, and the $\mathrm{C}+\mathrm{S}+\mathrm{P}$ combination suppressed the parameters to ultra-low levels in the presence of VPA. In order to demonstrate this result, single inhibitors and the $\mathrm{C}+\mathrm{S}+\mathrm{P}$ combination were assessed in the SCC- 15 and 5637 cell lines and similar results were obtained (Fig. $2 \mathrm{C}$ and D). It was observed that under $\mathrm{C}+\mathrm{S}+\mathrm{P}$ treatment, cells quickly lost cell viability, thus, 6 days was set as the termination time-point in the following experiments.

Inhibitor combination reduces VPA-induced cell migration. The present results revealed that VPA could induce EMT in 

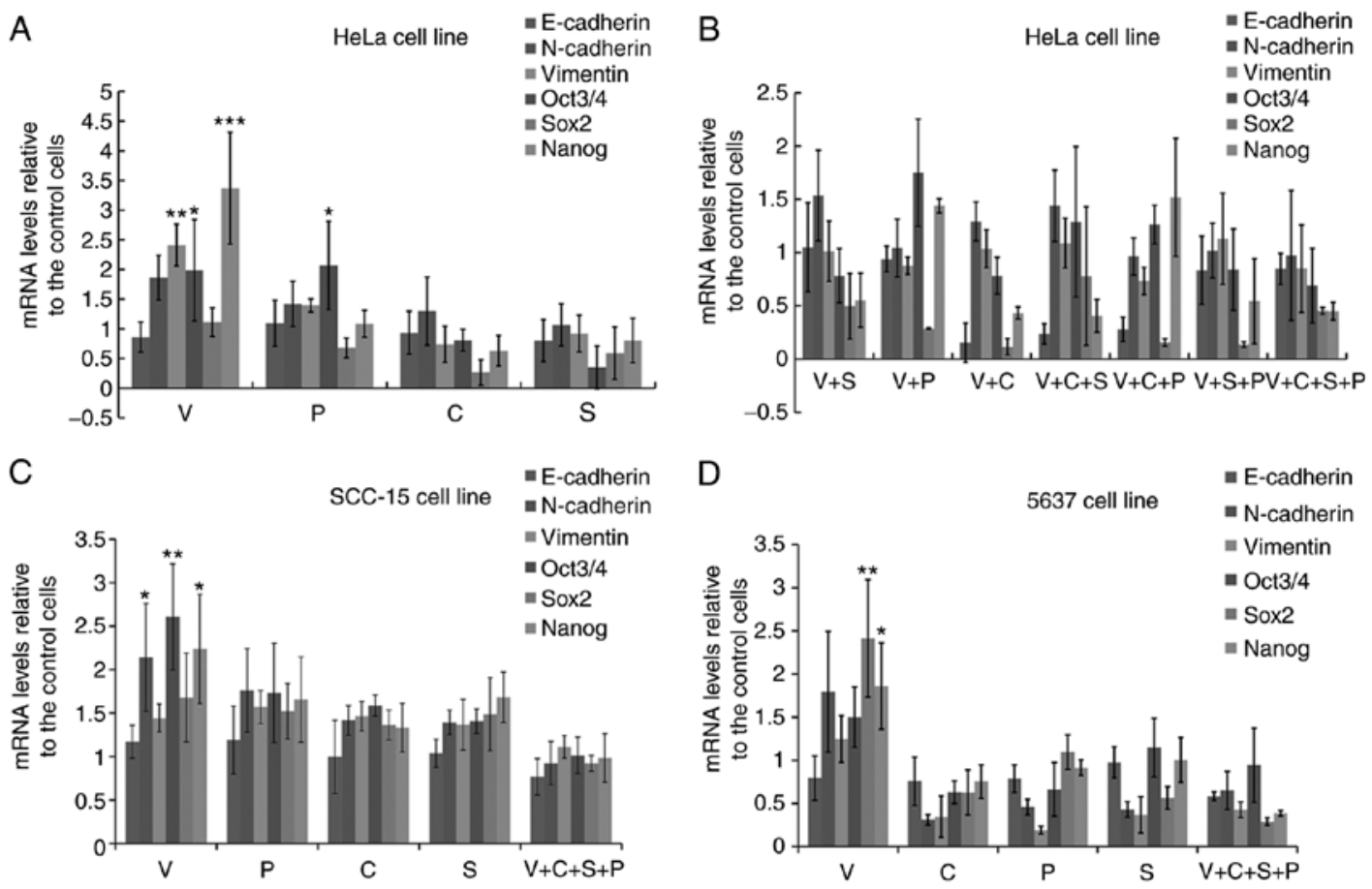

Figure 2. VPA promotes pluripotent transcription factor and EMT-related gene expression, and C+S+P (CHIR99021+SB431542+PD0325901) combination abrogates the effect of VPA. (A) Six-day VPA treatment upregulated the expression of pluripotent-related transcription factors and EMT-related genes and downregulated the MET-related E-cadherin gene in HeLa cells. (B) Inhibitor and combination of inhibitors suppressed Oct3/4, Sox2, Nanog, N-cadherin and vimentin expression down to differentiated levels in HeLa cells. (C) $\mathrm{C}+\mathrm{S}+\mathrm{P}$ combination suppressed Oct3/4, Sox 2, Nanog, N-cadherin and vimentin expression of SCC-15 cells in the presence of VPA. (D) $\mathrm{C}+\mathrm{S}+\mathrm{P}$ combination suppressed Oct3/4, Sox 2 , Nanog, N-cadherin and vimentin expression of 5637 cells in the presence of VPA. VPA, valproic acid; EMT, epithelial-mesenchymal transition; MET, mesenchymal-epithelial transition. ${ }^{*} \mathrm{P}<0.05,{ }^{* *} \mathrm{P}<0.01,{ }^{* * * *} \mathrm{P}<0.001$.

cultured cancer cells, and $\mathrm{C}+\mathrm{S}+\mathrm{P}$ could effectively inhibit VPA-induced EMT-related gene expression. Therefore, the three cell lines were then treated with $\mathrm{VPA}$ or $\mathrm{V}+\mathrm{C}+\mathrm{S}+\mathrm{P}$ for 6 days and the migration ability of these cells was evaluated. In VPA-treated cells, the number of migrated cells was increased compared with the DMSO-treated control cells, while the $\mathrm{C}+\mathrm{S}+\mathrm{P}$ combination effectively inhibited migration compared with the DMSO-treated control cells in the presence of VPA (SCC-15 cells: VPA/DMSO, 221.3 $\pm 13.05 / 124 \pm 16.37$, $\mathrm{P}<0.01 ; \mathrm{C}+\mathrm{S}+\mathrm{P} / \mathrm{DMSO}, 64.66 \pm 9.50 / 124 \pm 16.37, \mathrm{P}<0.05$; 5637 cells: VPA/DMSO, 203 $\pm 38.052 / 132.3 \pm 26.24, \mathrm{P}<0.05$; $\mathrm{C}+\mathrm{S}+\mathrm{P} / \mathrm{DMSO}, 34.6 \pm 10.6 / 132.3 \pm 26.24, \mathrm{P}<0.01$; HeLa cells: VPA/DMSO, 346.3 $\pm 62.7 / 168.3 \pm 22, \mathrm{P}<0.01 ; \mathrm{C}+\mathrm{S}+\mathrm{P} / \mathrm{DMSO}$, $67 \pm 11.2 / 168.3 \pm 22, \mathrm{P}<0.01)$ (Fig. $3 \mathrm{~A}$ and $\mathrm{B})$.

Inhibitor combination synergizes proliferation inhibition. Proliferation assays were next performed in cells treated with single inhibitor or combination treatments for 6 days. The single inhibitors had no effect on HeLa cell growth (Fig. 4A). The $\mathrm{C}+\mathrm{S}, \mathrm{C}+\mathrm{P}$ and $\mathrm{P}+\mathrm{S}$ treatments had various levels of inhibition $(\mathrm{C}+\mathrm{S}, 70 \pm 10 \%, \mathrm{P}<0.001 ; \mathrm{C}+\mathrm{P}, 72 \pm 9 \% \mathrm{P}<0.001$; $\mathrm{P}+\mathrm{S}, 70 \pm 11 \%, \mathrm{P}<0.001)$, with the $\mathrm{C}+\mathrm{S}+\mathrm{P}$ group exerting the strongest inhibitory effect compared with the DMSO-treated control cells $(\mathrm{C}+\mathrm{S}+\mathrm{P}, 80 \pm 2 \% \mathrm{P}<0.001)$. Strong growth inhibition was also revealed in the $\mathrm{C}+\mathrm{S}+\mathrm{P}$-treated $\mathrm{SCC}-15(69 \pm 7 \%$, $\mathrm{P}<0.001)$ and 5637 cells $(88 \pm 2 \%, \mathrm{P}<0.001)$ (Fig. 4B).

Inhibitor combination inhibits signal transduction. To evaluate the effects of the small molecules on inhibition of ALK, MEK and GSK3, western blot analysis of the phosphorylation

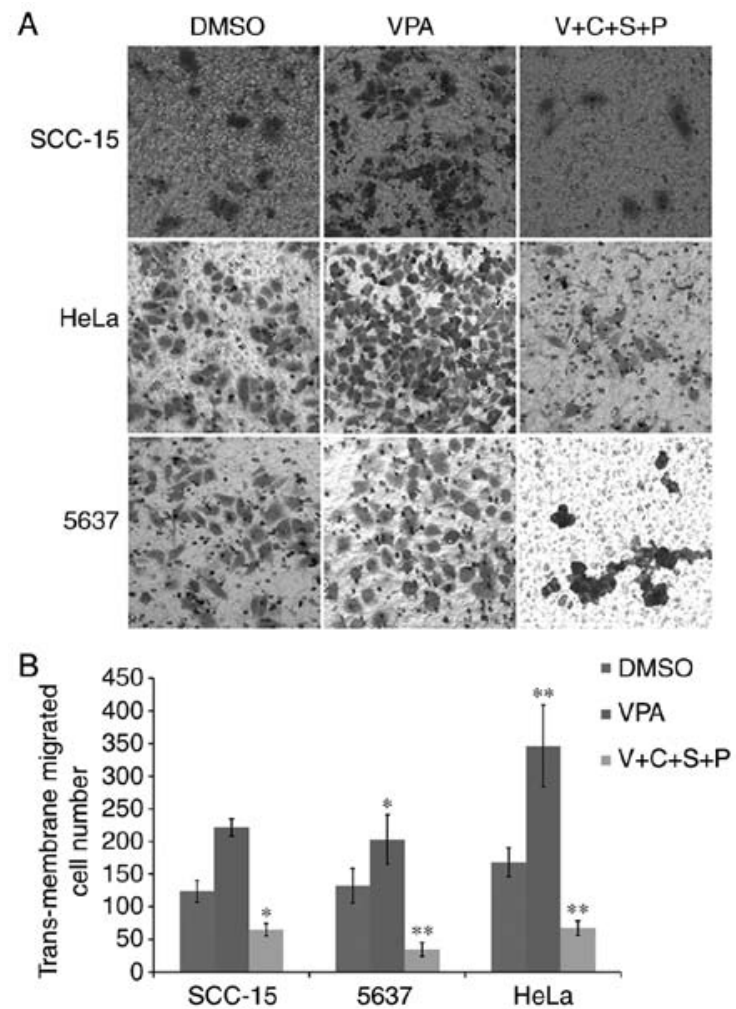

Figure 3. Inhibitor combination reduces VPA-induced cell migration in vitro. (A) Cells that invaded through to the underside of the Transwell filter after incubation with DMSO, VPA or V+C+S+P (valproic acid+CHIR99021+SB4 31542+PD0325901). Magnification, $x 100$. (B) VPA treatment increased the number of migrated cells and $\mathrm{V}+\mathrm{C}+\mathrm{S}+\mathrm{P}$ treatment decreased the number compared with the DMSO-treated cells; $\left({ }^{*} \mathrm{P}<0.05,{ }^{* *} \mathrm{P}<0.01\right)$. VPA, valproic acid; DMSO, dimethyl sulfoxide. 

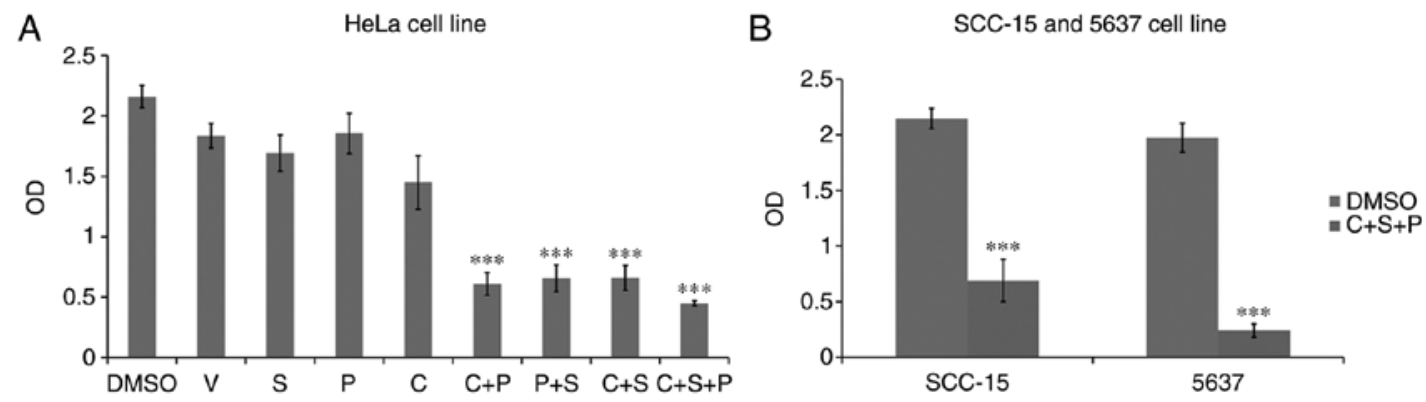

Figure 4. Inhibitor combination synergizes tumor cell proliferation inhibition. (A) Growth inhibition of single inhibitors and combination-treated HeLa cells compared with the DMSO-treated control cells. (B) Growth inhibition of C+S+P (CHIR99021+SB431542+PD0325901) combination-treated SCC-15 and 5637 cells compared with the DMSO-treated control cells. ${ }^{* * *} \mathrm{P}<0.001$. DMSO, dimethyl sulfoxide; OD, optical density.
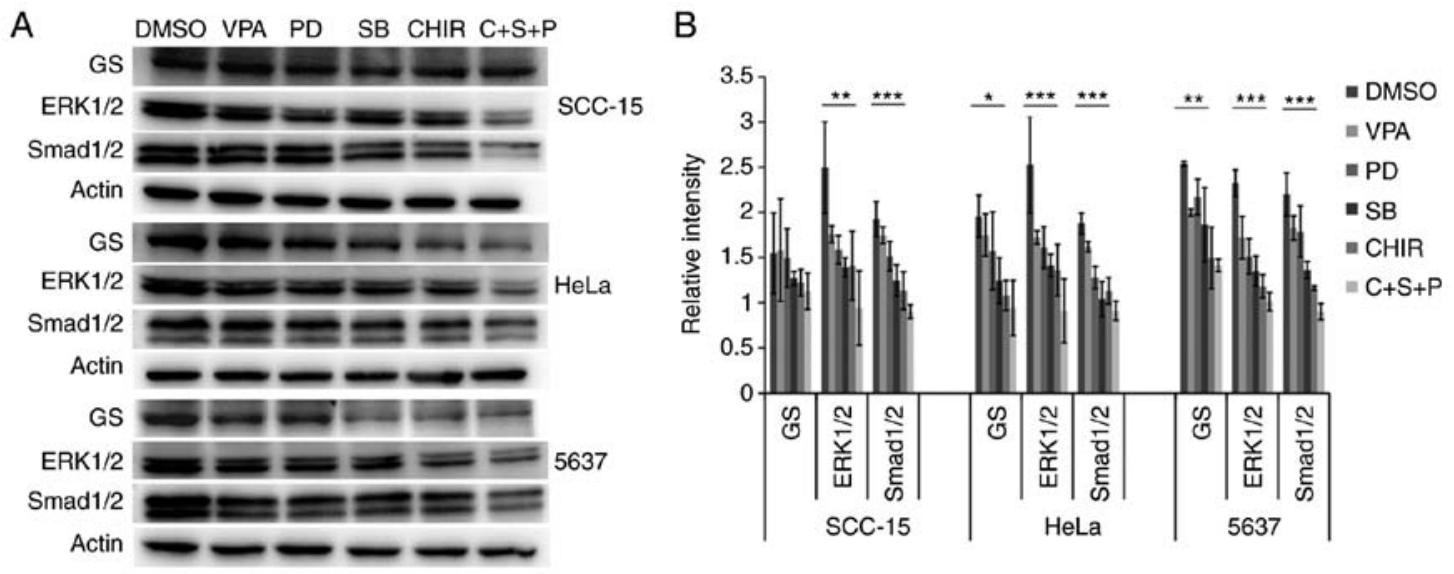

Figure 5. Inhibitor and combination of inhibitors suppresses phosphorylation levels of GS, ERK1/2 and Smad1/2 in treated cells. (A and B) Phosphorylation level detection of GS, ERK1/2 and Smad1/2 in treated cells. In HeLa, 5637 and SCC-15 cells, compared with DMSO-treated control cells VPA treatment did not significantly influence phosphorylation levels of GS, ERK1/2 and Smad1/2. In 5637 and HeLa cell lines, C+S+P (CHIR99021+SB431542+PD0325901) combination treatment markedly decreased phosphorylation levels of GS, ERK1/2 and Smad1/2. When PD0325901, SB431542 and CHIR99021 were used as single agents, significant inhibition to no self-target could be found. In the SCC-15 cell line, the C+S+P combination treatment significantly decreased phosphorylation levels of ERK1/2 and Smad1/2, without influencing GS, and there were significant cross-inhibitions to their targets when SB431542 and CHIR99021 were used as single agents. ${ }^{*} \mathrm{P}<0.05,{ }^{* *} \mathrm{P}<0.01,{ }^{* * *} \mathrm{P}<0.001$. VPA, valproic acid; DMSO, dimethyl sulfoxide.

levels of their respective targets Smad1/2, ERK1/2 and glycogen synthase (GS) was performed.

In all three cell lines, compared with the DMSO-treated cells, VPA treatment did not influence phosphorylation levels of any of the examined proteins. In 5637 and HeLa cell lines, $\mathrm{C}+\mathrm{S}+\mathrm{P}$ combination treatment significantly decreased phosphorylation levels of GS, ERK1/2 and Smad1/2, $(\mathrm{P}<0.05$, $\mathrm{P}<0.01$ and $\mathrm{P}<0.001$, respectively). In single treatment of PD0325901, SB431542 or CHIR99021, inhibition to no self-target could be found. In SCC-15 cells, $\mathrm{C}+\mathrm{S}+\mathrm{P}$ treatment significantly decreased phosphorylation levels of ERK1/2 and Smad1/2 ( $<<0.05$ and $\mathrm{P}<0.01$, respectively), without influencing GS, and these were cross-inhibitions to their targets when SB431542 and CHIR99021 were used as single agents (Fig. 5).

Inhibitor combination causes cell cycle arrest. The cell cycle was next investigated in cells treated with $\mathrm{C}+\mathrm{S}+\mathrm{P}$. PI and flow cytometry revealed that $\mathrm{C}+\mathrm{S}+\mathrm{P}$ exerted an increased cytostatic effect and induced S-phase accumulation in cells compared with DMSO-treated control cells (S-phase in C+S+P/DMSO HeLa cells: $25.9 \pm 0.66 \% / 11.9 \pm 0.718 \%, \mathrm{P}<0.01 ; 5637$ cells: $27.83 \pm 3.8 \% / 18.1 \pm 0.16 \%$; and SCC-15 cells: $25.33 \pm 1.1 \% / 19.23$ $\pm 3.16 \%$ ) (Fig. 6).
Inhibitor combination suppresses tumor cell sphere formation. The impact of inhibitors on sphere formation ability of these cells was next evaluated by culturing cells in cancer stem cell induction media containing VPA or V+C+S+P. In 4-6 days, small, bright, typical cell spheres were observed in SCC-15 and 5637 cell cultures, while spheres appeared in HeLa cell culture at days 8-10. In VPA-containing medium, cells formed compact, fast growing and large sized cell spheres compared with DMSO-treated control spheres. In $\mathrm{V}+\mathrm{C}+\mathrm{S}+\mathrm{P}$-containing medium, cells initially formed small-sized, atypical cell spheres that broke down into tiny lumps or single cells within 10 to 11 days (Fig. 7).

Inhibitor combination reduces $C D 24^{-} / C D 44^{+}$cell percentages in cancer cell spheres. The cells with $\mathrm{CD} 24^{-} / \mathrm{CD} 44^{+}$phenotype are regarded as cells that have cancer stem cell potential (31). Thus, the relative abundance of $\mathrm{CD} 24^{-} / \mathrm{CD} 44^{+}$cells in cell spheres was compared using fluorescence-activated cell sorting analysis. Compared with the DMSO-treated control cells, the CD24/CD44+ cell percentages in VPA-treated cells were increased, while the percentages in the $\mathrm{V}+\mathrm{C}+\mathrm{S}+\mathrm{P}$-treated cells were decreased (HeLa: VPA/DMSO, 59.8 $\pm 11.6 / 34.4 \pm 7.78, \mathrm{P}<0.05$; 

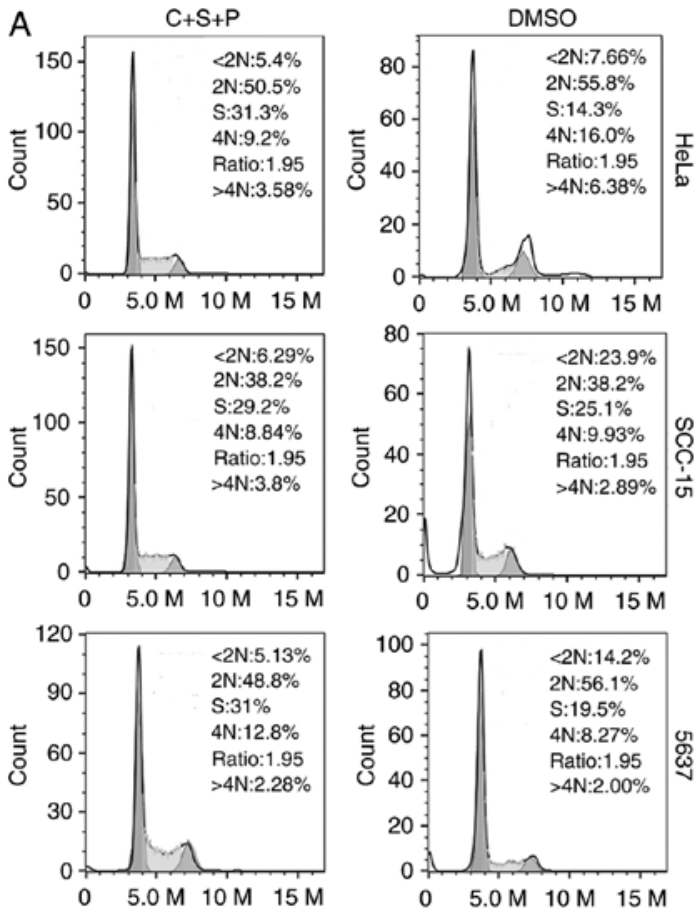

B

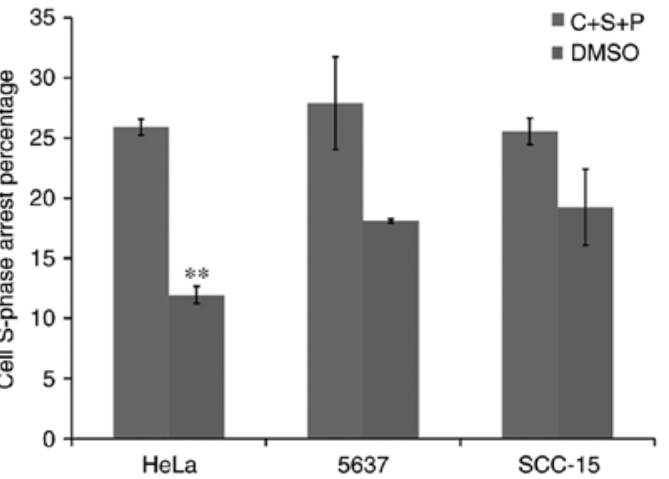

Figure 6. Inhibitor combination causes cytostatic growth arrest of tumor cells. (A) Cell cycle arrest analysis indicated that $\mathrm{C}+\mathrm{S}+\mathrm{P}$ combination caused $\mathrm{S}-\mathrm{phase}$ accumulation in HeLa, SCC-15 and 5637 cell lines. (B) Percentages of S-phase accumulation were increased in C+S+P-treated HeLa, SCC-15 and 5637 cell lines compared with the DMSO-treated control cells. ${ }^{* *} \mathrm{P}<0.01$. DMSO, dimethyl sulfoxide.

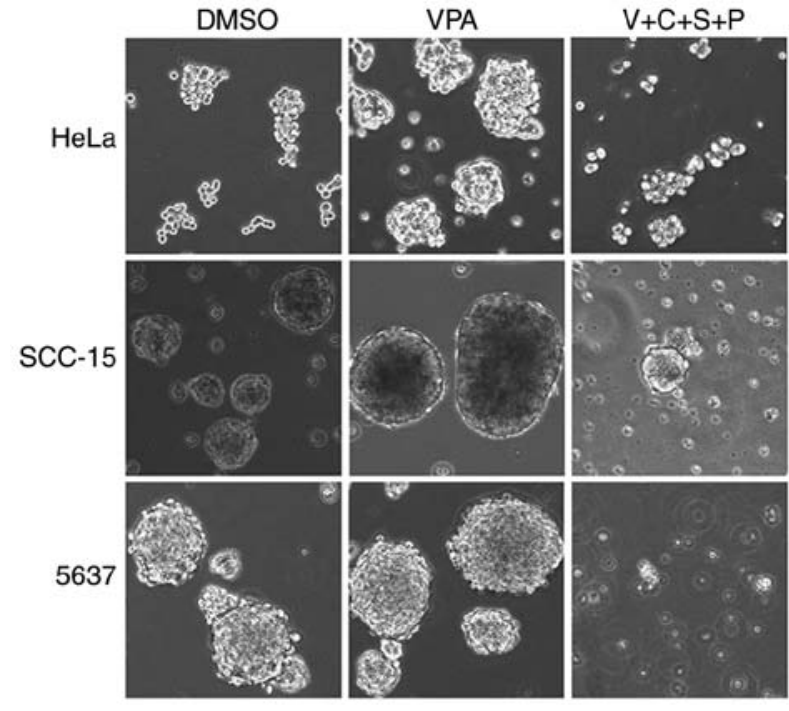

Figure 7. Inhibitor combination suppresses tumor cell sphere formation. VPA-containing medium promoted tumor cells to form compact, fast-growing and large-sized cell spheres. $\mathrm{V}+\mathrm{C}+\mathrm{S}+\mathrm{P}$ (valproic acid+CHIR99021+SB43154 2+PD0325901) combination inhibited tumor cell sphere formation compared with the DMSO-treated control (magnification, x100). VPA, valproic acid.

$\mathrm{V}+\mathrm{C}+\mathrm{S}+\mathrm{P} / \mathrm{DMSO}, 13.28 \pm 3.6 / 34.4 \pm 7.78 ; 5637: \mathrm{VPA} / \mathrm{DMSO}$, 67.3 $\pm 5.46 / 57.1 \pm 7.919 ; \mathrm{V}+\mathrm{C}+\mathrm{S}+\mathrm{P} / \mathrm{DMSO}, 12.03 \pm 2.6 / 57.1 \pm 7.9$, $\mathrm{P}<0.001$; SCC-15: VPA/DMSO, 57.72 $\pm 7.1 / 34.46$ 3.35, $\mathrm{P}<0.01$; $\mathrm{V}+\mathrm{C}+\mathrm{S}+\mathrm{P} / \mathrm{DMSO}, 10.26 \pm 2.5 / 34.46 \pm 3.35, \mathrm{P}<0.05)($ Fig. 8).

Inhibitor combination delays cancer cell clump formation in vivo. Cancer stem cells exhibit enhanced tumor-initiating capacity upon transplantation into a permissive host. Cells isolated from $\mathrm{VPA}$ and $\mathrm{V}+\mathrm{C}+\mathrm{S}+\mathrm{P}$-treated spheres were subcutaneously transplanted into the flanks of female athymic Swiss nude mice. The transplanted cells isolated from VPA-treated spheres formed a single visible solid cell clump beneath the injection site within 6 to 10 days. In mice that received cells from $\mathrm{V}+\mathrm{C}+\mathrm{S}+\mathrm{P}$-treated spheres, the single cell clump was invisible until 15 to 20 days after the injection. Cancer cell clumps were excised at day 30 after injection and weighed. Cell clumps from $\mathrm{V}+\mathrm{C}+\mathrm{S}+\mathrm{P}$-treated cells exhibited growth retardation compared with VPA-treated cells in all cell lines (VPA/V+C+S+P, HeLa: $346 \pm 119.53 \mathrm{mg} / 127 \pm 41.33 \mathrm{mg}$, $\mathrm{P}<0.01$; SCC-15: 270 $\pm 67.82 \mathrm{mg} / 98.4 \pm 28.33 \mathrm{mg}, \mathrm{P}<0.001$; 5637: 228 $\pm 19.63 \mathrm{mg} / 51.8 \pm 19.63 \mathrm{mg}, \mathrm{P}<0.001$ ) (Fig. 9).

\section{Discussion}

A small subpopulation of cancer cells within a heterogeneous tumor mass, termed CSCs, have the capacity to propagate, relapse, metastasize, and resist treatment. EMT plays a critical role in cancer progression, in which in situ carcinoma cells acquire mesenchymal characteristics and become mobile, leading to localized and metastatic invasion (15-21).

While many cancer therapies may effectively kill the bulk of tumor cells, failure to eliminate CSCs would enable the remaining CSCs to regenerate new tumors after treatment ends. Therefore, the complete elimination of CSCs is an issue of primary importance in cancer treatment $(32,33)$. Since CSCs account for only a small subpopulation of the entire cancer cell mass, direct isolation of these cells from tumor tissue for subsequent in vitro propagation is difficult. Without a sufficient number of CSCs, it is impossible to set up a screening system, with which to identify agents that are effective in eliminating CSCs. 

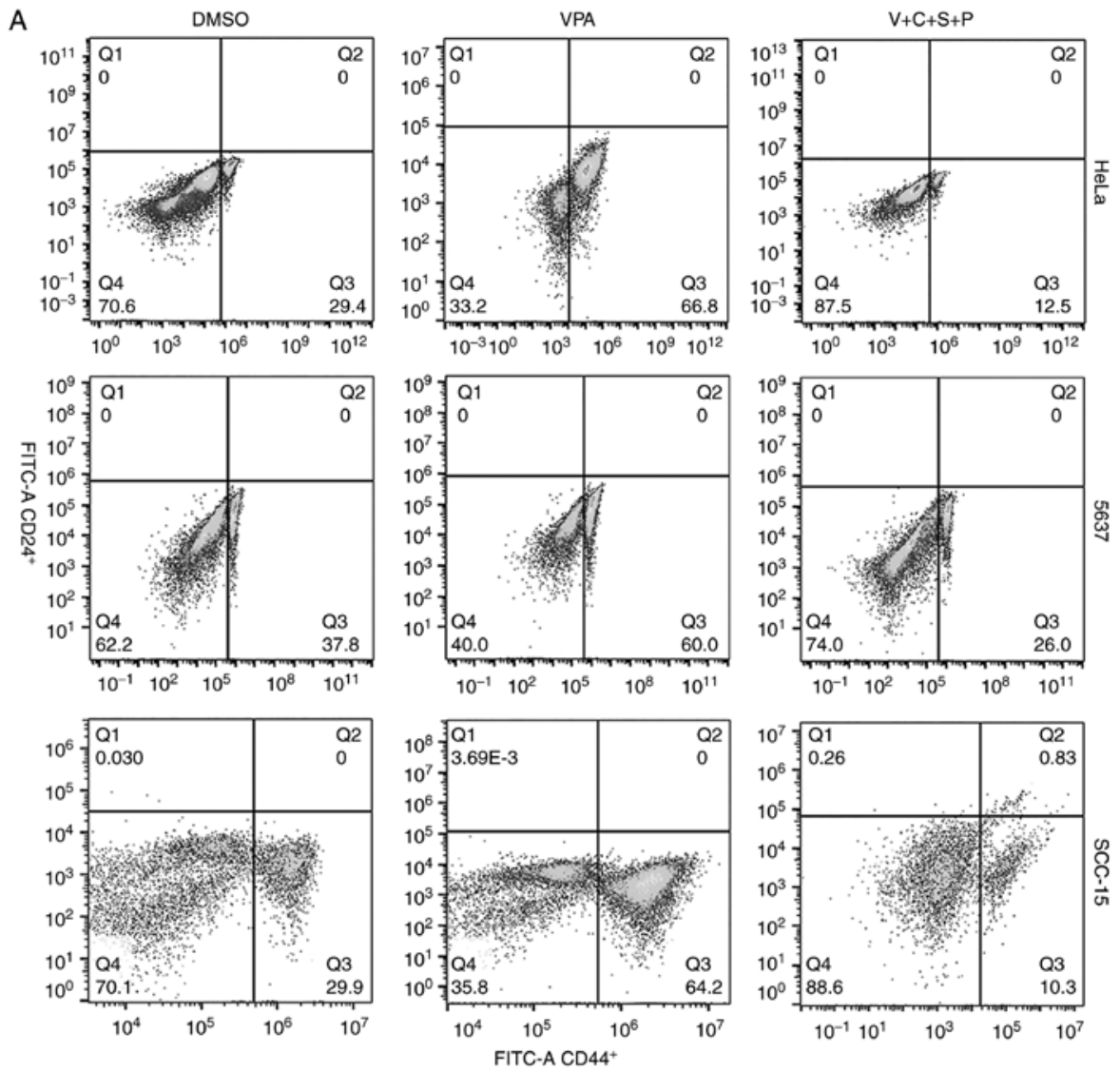

B

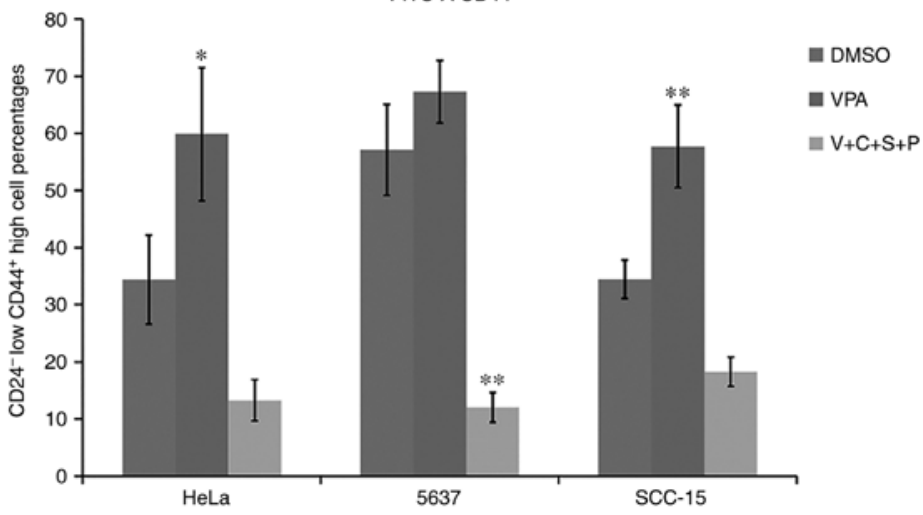

Figure 8. Inhibitor combination reduces CD24/CD44+ cell percentages in tumor cell spheres. (A) Flow cytometric analysis for CD24 /CD44 ${ }^{+}$cells (FITC-A $\mathrm{mAb}$ for detection of $\mathrm{CD} 24$; PE-A mAb for detection of CD44). (B) CD24/CD44+ cell percentages in VPA-treated HeLa, SCC-15 and 5637 cells were increased; in $\mathrm{V}+\mathrm{C}+\mathrm{S}+\mathrm{P}$-treated cells the percentages were significantly decreased compared with the DMSO-treated cells. ${ }^{*} \mathrm{P}<0.05$, ${ }^{* * *} \mathrm{P}<0.01$. VPA, valproic acid; DMSO, dimethyl sulfoxide.

In the present study, the results revealed that VPA induced EMT morphology in all three cell lines, as well as increased pluripotency and EMT-related gene expression, promoted cell migration and accelerated cell sphere formation. When the concentration was decreased to $0.25 \mathrm{mM}$, no effects were observed, and tumor cells treated with $1 \mathrm{mM}$ did not survive more than 5 days (data not shown). These observations indicated that different concentrations of VPA exhibit different effects on cell fate.

The other three inhibitors, PD0325901, SB431542 and CHIR99021, had no significant influence on EMT- and pluripotency-related gene expression, and cell proliferation rate. Proliferation inhibition was only revealed at high concentrations (4-6 $\mu \mathrm{m} / \mathrm{l})$ (data not shown). The combination treatments exhibited significant inhibition on cell growth and migration of all three cell lines, even in the presence of the EMT-promoting reagent VPA. This result indicated the effectiveness of the combination treatment in reversing VPA promotion of cancer cell invasiveness and stemness. It is possible that modulating the EMT status of cancer cells towards a more epithelial state may reduce the metastatic aggressiveness of cells and render cells more susceptible to conventional chemotherapy.

Western blot analyses demonstrated that in PD0325901, SB431542 and CHIR99021-treated 5637 and HeLa cell lines, there were cross reactions among their targets. In SCC-15 cells, treatment with a single inhibitor or $\mathrm{C}+\mathrm{S}+\mathrm{P}$ for 6 days had no impact on the phosphorylation levels of GS, and cross reactions occurred among the ERK1/2 and Smad1/2 pathways. 

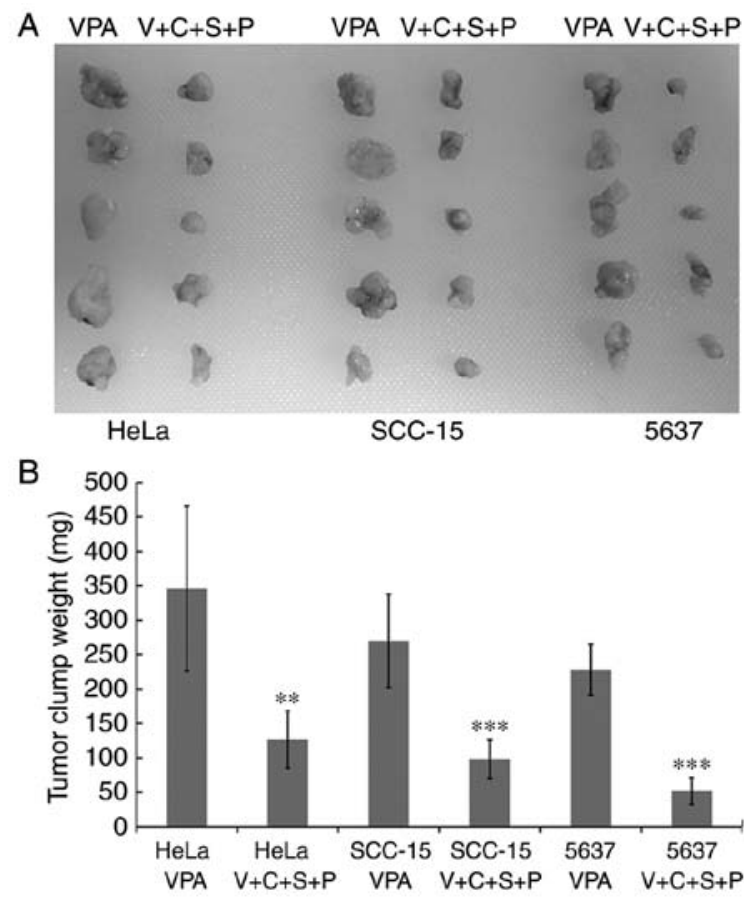

Figure 9. Inhibitor combination treatment delays cancer cell growth in vivo. (A) Image of representative HeLa, SCC-15 and 5637 cancer cell clumps from each treatment group. (B) $\mathrm{V}+\mathrm{C}+\mathrm{S}+\mathrm{P}$ (valproic acid+CHIR99021+SB 431542+PD0325901) combination treatment resulted in substantial cancer cell growth inhibition in HeLa, SCC-15 and 5637 cells compared with VPA-treated cells. ${ }^{* *} \mathrm{P}<0.01,{ }^{* * * *} \mathrm{P}<0.001$. VPA, valproic acid.

These results indicated that inhibitors have different cell-type specific effects. Therefore, we surmised that a multi-inhibitor treatment would be more advantageous in treating cancer cells, and this notion was demonstrated by our results revealing that the combination of PD0325901, SB431542 and CHIR99021 had significant synergized inhibition on phosphorylation of GS, ERK1/2 and Smad1/2. This synergized signaling pathway inhibition may cause cancer cell cycle arrest and result in cell growth suppression, as observed in the cell cycle and growth inhibition experiments of the present study.

Cancer stem cells form cell spheres in cancer stem cell induction medium and in the present study, the results revealed that VPA induced quick formation of cell spheres in all three cell lines, and the CD24-/CD $44^{+}$cell percentages were increased compared with the control group. This result indicated that $0.5 \mathrm{mM}$ VPA treatment could amplify the number of CSCs in these three cell lines, indicating that VPA may be a potent CSC stimulator for establishing a screening system to select potential anti-CSC agents. When cells were treated with all four inhibitors, the percentages of CD $24{ }^{-} / \mathrm{CD} 44^{+}$, the cell sphere forming ability and the in vivo tumor-initiating potential of tumor cells greatly decreased, demonstrating the effectiveness of this combination in eliminating CSCs in tumor cells, even in the presence of a CSC-promoting agent. These results were consistent with the qPCR results, in which $\mathrm{C}+\mathrm{S}+\mathrm{P}$ significantly downregulated VPA-mediated promotion of EMT and stemness-related gene expression.

VPA and the combination treatments were also assessed in other cell lines (CNE1, CNE2, MCF-7, CRL-2073 and J82; data not shown) and the same results were obtained with CNE2 and MCF-7 cells. CNE1, CRL-2073 and J82 cell lines were markedly sensitive to VPA and the combination treatment and could not survive more than 3 days. This sensitivity may be due to their slow-growing rate and less invasive and relatively higher epithelial-like differentiation characteristics (data not shown). Since CNE2 and MCF-7 cells are fast-growing and more invasive, similar to HeLa, SCC-15 and 5637 cells, we consider this CSC screening and inhibitory system more suitable in dealing with the highly invasive and fast-growing advanced malignant cancer cells.

In conclusion, in the present study, it was demonstrated that a specific concentration of VPA could be used as an agent to promote EMT and CSCs and establishing a screening system to identify agents for eliminating CSCs for advanced stage cancer. PD0325901, SB431542 and CHIR99021 co-treatment could act as a CSC eliminator by downregulating pluripotency and EMT-related gene expression and intervention with signal transduction pathways.

\section{Acknowledgements}

We thank Dr Zeng Zhang for technical assistance in the flow cytometric and cell cycle analysis.

\section{Funding}

The present study was supported by the Shenzhen Science and Technology Innovation Committee (grant nos. JCYJ 20160429090753103 and JCYJ20170816105345191); and the Guangdong Bureau of Traditional Chinese Medicine Project (grant no. 20171228).

\section{Availability of data and materials}

The datasets used and/or analyzed during the present study are available from the corresponding author on reasonable request.

\section{Authors' contributions}

YaZ performed the western blot analyses, quantitative real-time RT-PCR, tumor cell invasion assay and the cell cycle analysis; YuZ conducted the flow cytometric analysis, the cell growth inhibition test and the cell sphere formation; ML was responsible for the cell culture and cell sample preparation; FM carried out the cancer cell inoculation, the nude mice anesthetization and the cell clumps measurement; ZY assisted with the interpretation of the data, revision of the project and the statistical analysis; YC and GC contributed to the design and revision of the project, acquisition and analysis of the data, drafting, revising and publication of the manuscript, and were also responsible for all parts of the work being appropriately investigated. All authors read and approved the manuscript and agree to be accountable for all aspects of the research in ensuring that the accuracy or integrity of any part of the work are appropriately investigated and resolved.

\section{Ethics approval and consent to participate}

Animal experiment approval was obtained from the Ethics Committee of Peking University Shenzhen Hospital (Shenzhen, 
China). Chinese laws concerning animal caring and treatment were strictly followed during the experiments, and the study complied with ARRIVE guidelines (https://www.nc3rs.org. uk/arrive-guidelines).

\section{Patient consent for publication}

Not applicable.

\section{Competing interests}

The authors declare that they have no competing interests.

\section{References}

1. Shi Y, Do JT, Desponts C, Hahm HS, Scholer HR and Ding S: A combined chemical and genetic approach for the generation of induced pluripotent stem cells. Cell Stem Cell 2: 525-528, 2008.

2. Lin TX, Ambasudhan R, Yuan X, Li WL, Hilcove S, Abujarour R, Lin XY, Hahm HS, Hao E, Hayek A, et al: A chemical platform forimproved induction of human iPscs. Nat Methods 6: 805-808, 2009.

3. Huangfu DW, Osafune KJ, Maehr R, Guo WJ, Eijkelenboom A, Chen SB, Muhlestein W and Melton DA: Induction of pluripotent stem cells from primary human fibroblasts with only Oct4 and Sox2. Nat Biotechnol 26: 1269-1275, 2008.

4. Li YQ, Zhang Q, Yin XL, Yang WF, Du YY, Hou PP, Ge J, Liu C, Zhang WQ, Zhang X, et al: Generation of iPSCs from mouse fibroblasts with a single gene, Oct4, and small molecules. Cell Res 21: 196-204, 2011.

5. Ji MY, Lee EJ, Kim KB, Kim YM, Sung RY, Lee SJ, Kim DS and Park SM: HDAC inhibitors induce epithelial-mesenchymal transition in colon carcinoma cells. Oncol Rep 33: 2299-2308, 2015.

6. Vincent EE, Elder DJ, O'Flaherty L, Pardo OE, Dzien P, Phillips L, Morgan C, Pawade J, May MT, Sohail M, et al: Glycogen synthase kinase 3 protein kinase activity is frequently elevated in human non-small cell lung carcinoma and supports tumour cell proliferation. PLoS One 9: e114725, 2014.

7. Chua KN, Kong LR, Sim WJ, Ng HC, Ong WR, Thiery JP, Huynh $\mathrm{H}$ and Goh BC: Combinatorial treatment using targeted MEK and SRC inhibitors synergistically abrogates tumor cell growth and induces mesenchymal-epithelial transition in non-small-cell lung carcinoma. Oncotarget 6: 29991-30005, 2015.

8. Lu Y, Jiang F, Zheng X, Katakowski M, Buller B, To SS and Chopp M: TGF- $\beta 1$ promotes motility and invasiveness of glioma cells through activation of ADAM17. Oncol Rep 25: 1329-1335, 2011.

9. Noguchi S, Eitoku M, Moriya S, Kondo S, Kiyosawa H, Watanabe $\mathrm{T}$ and Suganuma N: Regulation of gene expression by sodium valproate in epithelial-to-mesenchymal transition. Lung 193: 691-700, 2015.

10. Hugo H, Ackland ML, Blick T, Lawrence MG, Clements JA, Williams ED and Thompson EW: Epithelial-mesenchymal and mesenchymal-epithelial transitions in carcinoma progression. J Cell Physiol 213: 374-383, 2007.

11. Thiery JP: Epithelial-mesenchymal transitions in tumour progression. Nat Rev Cancer 2: 442-454, 2002.

12. Kong D, Li Y, Wang Z, Banerjee S, Ahmad A, Kim HR and Sarkar FH: miR-200 Regulates PDGF-D-mediated epithelial-mesenchymal transition, adhesion, and invasion of prostate cancer cells. Stem Cells 27: 1712-1721, 2009.

13. Kong D, Banerjee S, Ahmad A, Li Y, Wang Z, Sethi S and Sarkar FH: Epithelial to mesenchymal transition is mechanistically linked with stem cell signatures in prostate cancer cells. PLoS One 5: e12445, 2010.

14. Kong D, Li Y, Wang Z and Sarkar FH: Cancer stem cells and epithelial-to mesenchymal transition (EMT)-phenotypic cells: Are they cousins or twins? Cancers 3: 716-729, 2011.

15. Li Y, VandenBoom TG II, Kong D, Wang Z, Ali S, Philip PA and Sarkar FH: Up-regulation of miR-200 and let-7 by natural agents leads to the reversal of epithelial-tomesenchymal transition in gemcitabine-resistant pancreatic cancer cells. Cancer Res 69: 6704-6712, 2009.
16. Singh A and Settleman J: EMT, cancer stem cells and drug resistance: An emerging axis of evil in the war on cancer. Oncogene 29: 4741-4751, 2010.

17. Robey RW, Chakraborty AR, Basseville A, Luchenko V, Bahr J, Zhan $\mathrm{Z}$ and Bates SE: Histone deacetylase inhibitors: Emerging mechanisms of resistance. Mol Pharm 8: 2021-2031, 2011.

18. Díaz-Núñez M, Díez-Torre A, Wever D, Andrade R, Arluzea J, Silió $\mathrm{M}$ and Aréchaga J: Histone deacetylase inhibitors induce invasion of human melanoma cells in vitro via differential regulation of $\mathrm{N}$-cadherin expression and RhoA activity. BMC Cancer 22: 667, 2016.

19. Pang L, Li Q, Wei C, Zou H, Li S, Cao W, He J, Zhou Y, Ju X, Lan J, et al: TGF- $\beta 1 /$ Smad signaling pathway regulates epithelial-to-mesenchymal transition in esophageal squamous cell carcinoma: In vitro and clinical analyses of cell lines and nomadic Kazakh patients from northwest Xinjiang, China. PLoS One 9: e112300, 2014.

20. Miao ZF, Zhao TT, Wang ZN, Miao F, Xu YY, Mao XY, Gao J, Wu Jh, Liu XY, You Y, et al: Transforming growth factor-beta1 signaling blockade attenuates gastric cancer cell-induced peritoneal mesothelial cell fibrosis and alleviates peritoneal dissemination both in vitro and in vivo. Tumour Biol 35: 3575-3583, 2014.

21. Kim YJ, Hwang JS, Hong YB, Bae I and Seong YS: Transforming growth factor beta receptor I inhibitor sensitizes drug-resistant pancreatic cancer cells to gemcitabine. Anticancer Res 32: 799-806, 2012.

22. Henderson YC, Chen Y, Frederick MJ, Lai SY and Clayman GL: MEK inhibitor PD0325901 significantly reduces the growth of papillary thyroid carcinoma cells in vitro and in vivo. Mol Cancer Ther 9: 1968-1976, 2010.

23. Chen X, Wu Q, Tan L, Porter D, Jager MJ, Emery C and Bastian BC: Combined PKC and MEK inhibition in uveal melanoma with GNAQ and GNA11 mutations. Oncogene 33: 4724-4734, 2014.

24. Marchand B, Tremblay I, Cagnol S and Boucher MJ: Inhibition of glycogen synthase kinase-3 activity triggers an apoptotic response in pancreatic cancer cells through JNK-dependent mechanisms. Carcinogenesis 33: 529-537, 2012.

25. Lackner MR, Wilson TR and Settleman J: Mechanisms of acquired resistance to targeted cancer therapies. Future Oncol 8: 999-1014, 2012.

26. Yun $\mathrm{CH}$, Mengwasser KE, Toms AV, Woo MS, Greulich H, Wong KK, Meyerson M and Eck MJ: The T790M mutation in EGFR kinase causes drug resistance by increasing the affnity for ATP. Proc Natl Acad Sci USA 105: 2070-2075, 2008.

27. Buck E, Eyzaguirre A, Rosenfeld-Franklin M, Thomson S, Mulvihill M, Barr S, Brown E, O'Connor M, Yao Y, Pachter J, et al: Feedback mechanisms promote cooperativity for small molecule inhibitors of epidermal and insulin-like growth factor receptors. Cancer Res 68: 8322-8332, 2008.

28. Fukumoto S, Kanbara K and Neo M: Synergistic anti-proliferative effects of mTOR and MEK inhibitors in high-grade chondrosarcoma cell line OUMS-27. Acta Histochem 120: 142-150, 2018.

29. Langlands AJ, Carroll TD, Chen Y and Näthke I: Chir99021 and Valproic acid reduce the proliferative advantage of Apc mutant cells. Cell Death Dis 9: 255, 2018.

30. Livak KJ and Schmittgen TD: Analysis of relative gene expression data using real-time quantitative PCR and the $2-\Delta \Delta C \mathrm{~T}$ method. Methods 25: 402-408, 2001.

31. Lee YJ, Wu CC, Li J, Ou CC, Hsu SC, Tseng HH, Kao MC and Liu JY: A rational approach for cancer stem-like cell isolation and characterization using CD44 andprominin-1(CD133) as selection markers. Oncotarget 7: 78499-78515, 2016.

32. Blake RA, Broome MA, Liu X, Wu J, Gishizky M, Sun L and Courtneidge SA: SU6656, a selective src family kinase inhibitor, used to probe growth factor signaling. Mol Cell Biol 20: 9018-9027, 2000.

33. Marchion D and Munster P: Development of histone deacetylase inhibitors for cancer treatment. Expert Rev Anticancer Ther 7: 583-598,2007. 